\title{
Towards a national child and adolescent health strategy in Switzerland: strengthening surveillance to improve prevention and care
}

\author{
Julia Dratva ${ }^{1,2,6} \cdot$ Susanne Stronski ${ }^{3} \cdot$ Arnaud Chiolero $^{4,5}$ \\ Received: 12 November 2017 / Accepted: 21 November 2017 / Published online: 28 November 2017 \\ (C) Swiss School of Public Health (SSPH+) 2017
}

\section{From surveillance to evidence-based public health}

In recent years, Switzerland developed two overarching health strategies: one on health in general [Federal Office of Public Health (FOPH) (Bundesamt für Gesundheit) 2013] and one on the prevention of non-communicable diseases (NCD) [Federal Office of Public Health (FOPH) (Bundesamt für Gesundheit) 2016]. Both strategies allude to children and adolescents as vulnerable populations and to childhood as a relevant life phase for adult-onset diseases. While the European community has launched a child and adolescent health strategy (WHO Europe 2014), a specific strategy for children and adolescents is still missing in Switzerland. This lack of a health strategy for society's youngest age group partly explains the lack of an age-specific surveillance concept.

Switzerland's most challenging health issues relate to the burden of non-communicable diseases and mental disorders, both in adults and children. Within a life course perspective, evidence supporting the long-term health consequences of early life exposures and risks is abundant

Julia Dratva

julia.dratva@zhaw.ch

1 ZHAW School of Health Professions, Institute of Health Sciences, Winterthur, Switzerland

2 Swiss Tropical and Public Health Institute, Basel, Switzerland

3 Independent Consultant Child, Adolescent and School Health, Bern, Switzerland

4 Institute of Social and Preventive Medicine (IUMSP), Lausanne University Hospital, Lausanne, Switzerland

5 Institute for Primary Health Care (BIHAM), University of Bern, Bern, Switzerland

6 University of Basel, CH, Petersplatz 1, 4031 Basel, Switzerland
(Newham and Ross 2009). For example, obese children have a higher risk of developing chronic conditions such as heart disease (Umer et al. 2017). Most adult smokers became addicted to tobacco in adolescence (Johnston et al. 2012). Early mental disorders are linked to early and persistent substance abuse, school dropout, and early disability or self-harm (Henderson et al. 2017).

Recent national reports highlighted the relative paucity of data on health and health determinants of children and adolescents, on utilisation of, and access to health services [Dratva et al. 2013; Swiss Health Observatory (OBSAN) 2015]. In particular, data from paediatricians and general practitioner who diagnose and treat most children are not accessible, neither to policy makers nor to researchers. Mental health and developmental delays are health topics on which very little is known and even for many physical chronic conditions, such as asthma or hypertension, no recent prevalence data exist.

Evidence-based public health needs readily available high quality data for policy makers and professionals to take adequate preventive action and set priorities, to plan, implement and evaluate health care and health promotion, and enable pediatric health service research. Such data need to be available on a national but also on a regional and sub-regional level, as well as by socioeconomic and cultural characteristics to address the actual public health needs (Alexander et al. 2015; Bringolf-Isler et al. 2015).

\section{Bringing stakeholders together...}

With the support of the Swiss School of Public Health, the workshop "Toward a national child and adolescent surveillance system" took place at the University of Basel in February 2017. The goal was to bring together stakeholders from various sectors, identify relevant health indicators, and thereby contribute to the building of a 
Table 1 Additional child and adolescent health themes and indicators for a comprehensive non-communicable disease indicator set (recommended by workshop participants "Toward a national child and adolescent surveillance system" February 2017, Basel, Switzerland)

\begin{tabular}{|c|c|}
\hline Theme & Set of indicators \\
\hline $\begin{array}{l}\text { Physical and biological environmental } \\
\text { determinants }\end{array}$ & $\begin{array}{l}\text { a. Exposure to road traffic (noise, air pollution, and various chemical exposures) } \\
\text { b. School physical environment (temperature, air quality, noise, hygiene) } \\
\text { c. Child-friendliness of neighbourhoods (playgrounds, safety, environmental exposures, green space, } \\
\text { child-specific needs) }\end{array}$ \\
\hline Socio-economic environment & $\begin{array}{l}\text { a. Family relationships and parental stressors } \\
\text { b. Life style and health risks shared by families in general and specifically exposure to violence at } \\
\text { home } \\
\text { c. Access to higher schooling and educational measures }\end{array}$ \\
\hline Competences and resilience & $\begin{array}{l}\text { a. Subjective perception of health and well-being (age groups }<15 \text { years) } \\
\text { b. Self-efficacy } \\
\text { c. Social support network (child and its family) } \\
\text { d. Knowledge and decision-making skills regarding: environmental exposures, nutrition, addictive } \\
\text { substances, media, sexuality }\end{array}$ \\
\hline Health outcomes & $\begin{array}{l}\text { a. Child somatic, cognitive, language, motor, psychosocial development } \\
\text { b. Prevalence and incidence of chronic health conditions }\end{array}$ \\
\hline $\begin{array}{l}\text { Access to health care services and health } \\
\text { promotion }\end{array}$ & $\begin{array}{l}\text { a. Access to health care and utilisation across the life course } \\
\text { b. Utilisation rate of preventive medical examinations } \\
\text { c. Workforce of health care services (adequacy of training, staffing) } \\
\text { d. Access to/quality of health promotion }\end{array}$ \\
\hline
\end{tabular}

genuine surveillance and information system. More than 50 experts in childhood and adolescence public health from medicine, psychology, sociology, and economy, researchers, health care professionals, and employees of cantonal and federal authorities, met at the workshop to review, prioritise and extend the list of NCD-indicators recently published by the BAG (Ruch 2016). The themes discussed and the proposed additional NCD indicators are summarized in Table 1.

\section{Call for a national child and adolescent health strategy}

The European Child and Adolescent health strategy 2015-2020 (WHO Europe 2014) addresses the need of specific national public health strategies and surveillance systems, as have been developed and established by many neighbouring countries, in the overall aim of safeguarding and improving health of children and adolescents. Swiss experts attending the workshop expressed a high urgency to follow suit. We therefore call for a specific national child and adolescent health strategy, alongside with the development of a sustainable and comprehensive health surveillance system accompanied by child and adolescent public health research.

\section{References}

Alexander D, Rigby M, Gissler M, Köhler L, MacKay M (2015) The challenge of compiling data profiles to stimulate local preventive health action: a European case study from child safety. Int J Public Health 60:449-456. https://doi.org/10.1007/s00038-0150665-z

Bringolf-Isler B, Mäder U, Dössegger A, Hofmann H, Puder JJ, Braun-Fahrländer C, Kriemler S (2015) Regional differences of physical activity and sedentary behaviour in Swiss children are not explained by socio-demographics or the built environment. Int J Public Health 60:291-300. https://doi.org/10.1007/s00038014-0645-8

Dratva J, Späth A, Zemp E (2013) Child and adolescent health monitoring-report for the federal office of statistics (Kinderund Jugend- Gesundheitsmonitoring in der Schweiz-Bericht z.H. des BFS). Paper presented at the Swiss Public Health Conference, Zürich

Federal Office of Public Health (FOPH) (Bundesamt für Gesundheit) (2013) Health 2020 (Gesundheit2020). https://www.bag.admin. $\mathrm{ch} / \mathrm{bag} / \mathrm{en} / \mathrm{home} /$ themen/strategien-politik/gesundheit-2020.html. Accessed 11 Nov 2017

Federal Office of Public Health (FOPH) (Bundesamt für Gesundheit) (2016) National Strategy for Prevention of Non-Communicabel Diseases (Nationale Strategie Prävention nichtübertragbarer Krankheiten). https://www.bag.admin.ch/bag/en/home/themen/ strategien-politik/nationale-gesundheitsstrategien.html. Accessed 11 Nov 2017

Henderson JL, Chaim G, Hawke LD, National Youth Screening Project N (2017) Screening for substance use and mental health problems in a cross-sectoral sample of Canadian youth. Int J Ment Health Syst 11:21. https://doi.org/10.1186/s13033-017-0128-4 
Johnston V, Liberato S, Thomas D (2012) Incentives for preventing smoking in children and adolescents. Cochrane Database Syst Rev. https://doi.org/10.1002/14651858.CD008645.pub2

Newham JP, Ross MG (2009) Early life orgins of human health and disease. Karger, Basel

Ruch N (2016) Datenquellen für das NCD-monitoring-system. https:// www.bag.admin.ch/bag/de/home/service/ressortforschung-eva luation/forschung-im-bag/forschung-nichtuebertragbare-kran kheiten/monitoring-systemncd.html. Accessed 11 Nov 2017

Swiss Health Observatory (OBSAN) (2015) National Health Report 2015 (Gesundheit in der Schweiz-Fokus chronische
Erkrankungen. Nationaler Gesundheitsbericht 2015) Hogrefe Verlag http://www.obsan.admin.ch/en. Accessed 11 Nov 2017

Umer A, Kelley GA, Cottrell LE, Giacobbi P Jr, Innes KE, Lilly CL (2017) Childhood obesity and adult cardiovascular disease risk factors: a systematic review with meta-analysis. BMC Public Health 17:683. https://doi.org/10.1186/s12889-017-4691-z

WHO Europe (2014) Investing in children: the European child and adolescent health strategy 2015-2020. http://www.euro.who.int/ en/health-topics/Life-stages/child-and-adolescent-health/policy/ investing-in-children-the-european-child-and-adolescent-healthstrategy-20152020. Accessed 11 Nov 2017 